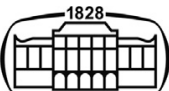

AKADÉMIAI KIADÓ

Journal of Behavioral Addictions

9 (2020) 4, 1098-1102

DOl:

$10.1556 / 2006.2020 .00091$

(c) 2020 The Author(s)

\title{
Substitute addictions in the context of the COVID-19 pandemic
}

\section{DEBORAH LOUISE SINCLAIR ${ }^{1,2^{*}} \odot$, WOUTER VANDERPLASSCHEN ${ }^{2}$, SHAZLY SAVAHL ${ }^{3}$, MARIA FLORENCE ${ }^{1}$, DAVID BEST $^{4}$ and STEVE SUSSMAN ${ }^{5}$}

\author{
${ }^{1}$ Department of Psychology, University of the Western Cape, Cape Town, South Africa \\ ${ }^{2}$ Department of Special Needs Education, Ghent University, Ghent, 9000, Belgium \\ ${ }^{3}$ Centre for Interdisciplinary Studies on Children, Families and Society, University of the Western \\ Cape, Cape Town, South Africa \\ ${ }^{4}$ Department of Criminology and Social Sciences, University of Derby, Derby, UK \\ ${ }^{5}$ Institute for Health Promotion and Disease Prevention, University of Southern California, Los \\ Angeles, CA, USA
}

\section{CASE REPORT

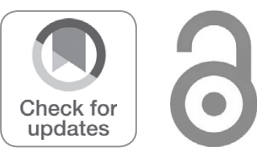

Received: June 23, 2020 • Revised manuscript received: September 23, 2020; October 17, 2020 • Accepted: October 25, 2020 Published online: November 16, 2020

\begin{abstract}
The global spread of COVID-19, subsequent stay-at-home requirements, spatial distancing measures, and long-term isolation present additional challenges for persons in recovery. Using an illustrative case from South Africa, we discuss COVID-19 related pornography use through the lens of relapse and substitute addiction. South Africa is the epicenter of the pandemic in Africa, and has issued an alcohol and cigarette ban. Historical examples suggest that responses to forced abstinence may include compliance and abstinence, but also seeking alternatives to the original addiction and substitution. Substitution of alternative activities/objects may provide similar appetitive effects to fill the void of the terminated addictive behavior, temporarily or in the long-term. While substitutes do not necessarily portend a relapse, coupled with isolation and reduced recovery support, they can potentiate relapse to the former or 'new' addictive behavior. Addiction professionals should be aware of the potential for such negative impacts during and after the COVID-19 pandemic.
\end{abstract}

\section{KEYWORDS}

substitute addictions, recovery, coronavirus, COVID-19

\section{INTRODUCTION}

The global spread of COVID-19, subsequent stay-at-home requirements, long-term isolation, and spatial distancing measures present additional challenges for persons in recovery (Marsden et al., 2020). In South Africa, the epicenter of the pandemic in Africa, lockdown regulations have included a ban on the sale and purchase of alcohol (instituted on 27 March, repealed on 1 June, reinstated on 12 July and lifted on 17 August 2020) and cigarettes (from 27 March to 17 August 2020). Amidst state-mandated, forced abstinence (e.g. Castro-Calvo, Ballester-Arnal, Potenza, King, \& Billieux, 2018), there have been reports of surges in illicit trade and theft of cigarettes and alcohol (Luthuli, 2020; Mokone, 2020) and the production and (at times) fatal consumption of home-brewed alcohol (Pyatt, 2020). While a significant decline in alcohol consumption levels has been anticipated (Marsden et al., 2020), historical examples suggest that for those with addictions to nicotine or alcohol, substitute/cross addictions may emerge subsequent to compliance with the regulations or a long-term commitment to abstinence. That is, responses to forced abstinence may include compliance and abstinence, but also seeking alternatives for the original addiction and substitution. Using E-mail: deborahlouisesinclair@gmail. com
*Corresponding author. 
an illustrative case from South Africa, we discuss COVID19-related pornography use through the lens of relapse and substitute addictions.

Substitute addictions represent the replacement of one addictive behavior by another (Sussman, 2017). A replacement may fill the void of the terminated addictive behavior, temporarily or in the long-term, providing similar appetitive effects. Temporary replacements can occur during forced abstinence, ending if the substitute does not serve expected functions or when the primary addictive activity/object again becomes available (Sinclair et al., 2020). A replacement/substitute may be linked to one's addiction history and is not only related to the abstained behavior (i.e., as a compensatory behavior; Castro-Calvo et al., 2018); is contingent on availability and accessibility, the extent to which it yields tolerable withdrawal symptoms, and the contexts within which it is engaged (e.g., socially or alone, Sussman et al., 2011). Based on available studies, most substitution involves the exchange of substances. For example, responses to Operation Intercept, a US public policy enforced between 21 September - 2 October 1969 to control the import of marijuana and other substances across the US-Mexico border, included abstention, decreased use and substitution (Gooberman, 1974). Substitutes, including hashish, alcohol, barbiturates, amphetamines, cocaine and heroin, were experimented with during the shortage or had been used previously (Gooberman, 1974). Similarly, responses to the Australian "heroin drought" of 2000/2001 that was characterized by increased cost, lower quality and shortages in the availability of heroin were: declining use, fewer overdoses, substitution with cocaine, cannabis, amphetamines and benzodiazepines (Degenhardt, Day, Gilmour, \& Hall, 2006; Weatherburn, Jones, Freeman, \& Makkai, 2003) and the development of a home-grown methamphetamine market. Substances have also been substituted with compulsive behaviors such as pornography viewing (Tadpatrikar \& Sharma, 2018).

A marked increase in pornography consumption has been observed during the COVID-19 pandemic (Mestre-Bach, Blycker, \& Potenza, 2020), as online and solo activities may be used to compensate for limited in-person social contact including partnered sex (Lehmiller, Garcia, Gesselman, \& Mark, 2020) and/or cope with pandemic-related emotional states (Grubbs, 2020). However, the extent to which these behaviors are time-limited or enduring sequelae of the pandemic is unknown (Mestre-Bach et al., 2020). Although high-frequency use on its own is not indicative of problematic pornography use (PPU), PPU is engaged in frequently (Böthe, Tóth-Király, Potenza, et al., 2020). Some individuals with PPU will display disordered or addictive use, leading to psychological distress (Király et al., 2020), problems in romantic relationships (Szymanski \& Stewart-Richardson, 2014) and sexual functioning (Böthe, Tóth-Király, Griffiths, et al., 2020). Persons exhibiting PPU as a substitute addiction, however, may be at heightened risk of relapse. Risk factors for relapse include being disconnected from the structure, social identity and belonging provided by recovery support networks (Dekkers, Vos, \& Vanderplasschen, 2020), feeling powerless (Mestre-Bach et al., 2020) and isolated when urges to use arise (Volkow, 2020). During forced abstinence, when the individual is prevented from engaging in a given activity, reverse salience may arise whereby the abstained behavior dominates thoughts and actions and becomes the most important (Griffiths, 2005).

Compulsive Sexual Behavior Disorder (CSBD) is defined as "a persistent pattern of failure to control intense, repetitive sexual impulses or urges, resulting in repetitive sexual behavior over an extended period (e.g., six months or more) that causes marked distress or impairment in personal, family, social, educational, occupational or other important areas of functioning" (Kraus et al., 2018, p. 109). CSBD is generally more prevalent in men (Kraus et al., 2018). In Böthe, Potenza and colleagues' (2020) recent study, the CSBD-19 Scale was administered to 9,325 adults in Germany, the US and Hungary, yielding prevalence estimates of $4.2-7 \%$ and $0-5.5 \%$ for high risk of CSBD among men and women respectively. In an earlier survey by Dickenson, Gleason, Coleman, and Miner (2018) in the United States, $8.6 \%$ ( $7 \%$ of women and $10.3 \%$ of men) of a representative sample of adults $(\mathrm{N}=2,325)$ endorsed the defining feature of CSBD, that of clinically significant emotional distress and/or impairment over a loss of control of sexual impulses, feelings and behaviors.

CSBD has high comorbidity with Substance Use Disorders (SUDs) (Kraus et al., 2018). For example, in a South African study, $54 \%$ of persons receiving specialized treatment for a SUD screened positive for either gambling or sex addiction, or both (Keen, Sathiparsad, \& Taylor, 2015). CSBD has also been associated with a lifetime history of sexual abuse, particularly among men (Slavin, Blycker, et al., 2020; Slavin, Scoglio, Blycker, Potenza, \& Kraus, 2020). Unprocessed childhood trauma is an often unidentified etiological factor in the development of (interconnected) addictive behaviors (Lim, Cheung, Kho, \& Tang, 2020; Sundin \& Lilja, 2019; Young, 1990).

Below, we present JP's illustrative case to elucidate the mechanisms of substitute addictions and, specifically, relapse during the lockdown in South Africa. Where recovery from SUDs is operationalized as a willingly maintained daily life of sobriety, citizenship and personal health (The Betty Ford Institute Consensus Panel, 2007), JP's relapse process can be traced along a series of mini-decisions: disconnecting from recovery support; attempting to sext a woman and bargaining with himself about watching pornography. While ostensibly insignificant, these decisions - collectively facilitated relapse (Marlatt \& George, 1984). Bargaining about which situations, times and objects of addiction are "permissible" for engagement is indicative of imminent physical relapse in the absence of effective coping skills (Kalema et al., 2019; Melemis, 2015).

\section{CASE REPORT}

$\mathrm{JP}$ is a 50 -year-old man in recovery from an alcohol use disorder and member of Alcoholics Anonymous (AA) for 25 
years. He first experienced alcohol around the age of 7, while his "drinking career" started at age 15. JP believes that alcohol changed his personality, making him less shy, enabling him to communicate and suppressing his interest in romantic relationships, which he then feared when sober. Before he began viewing pornography, early acting out involved fantasizing; reading women's magazines, and stealing romance novels and visualizing the sexual content. He withdrew from family life which had been characterized by his mother's partner's violence and substance use. From ages 16 to 20 , he was sexually abused by an older male. He also now recognizes "flirtatious" behaviors of older cousins as child abuse. At age 24, when his father figure advised him to "do something about" his drinking behavior, he contacted AA and within two days had attended his first meeting. Yet, in hindsight, he identifies that for 20 years he behaved like " $a$ dry drunk" and that "underlying issues surfaced".

When becoming sober, he desired a romantic relationship, primarily to live out sexual fantasies. However, this conflicted with his calling to become a Catholic priest and, at age 25, he entered a seminary. During his training, compulsive masturbation continued. He engaged in two relationships: one with a married female congregant and another that motivated him to terminate his training. $\mathrm{He}$ became a recovery assistant in 2008, drawing on his addiction and recovery career to support treatment and aftercare.

After encountering Sex and Love Addicts Anonymous (SLAA) through work, JP began attending meetings in 2019. Participation led to another "spiritual awakening" and the recognition of long-term behaviors as a sex and love addiction (struggling in relationships; choosing unavailable women; viewing pornography and masturbating compulsively). JP believes that his (pornography) "addiction was always there," but escalated with alcohol abstinence; he equates it with "taking that first drink." That is, he viewed his sex addiction as a substitute for his alcohol addiction. How he accessed pornography changed over time: from watching DVDs, to having a selection on a flash drive; Googling images and viewing websites from his phone. He resisted acquiring a smartphone until age 40 for fear of intensifying his pornography viewing. Using his phone enables him to view pornography whenever he wants and wherever he is located. Although he was "scared" initially, he now uses his phone to access content that is tailored to "fulfil" his sexual fantasies. His current girlfriend (who is having an extra-marital affair with JP) regards his pornography use as a betrayal. However, when viewing pornography, he is "glued" to his phone; "can't get enough" and is "obsessive" which is "scary" for him. He stopped viewing pornography "a few weeks before the lockdown".

The announcement of South Africa's lockdown on March 23rd, 2020 coincided with his last in-person AA meeting. Two weeks into the lockdown, JP participated in his first online AA meeting and later an SLAA meeting. However, concerned about anonymity and high mobile data costs, he stopped participation in SLAA meetings. Quarantine policies also prohibited contact with his girlfriend and JP expressed feeling sexually frustrated, lonely and "longing for intimacy." He experienced a "slip" after his request to exchange texts of a sexually intimate nature with a woman he had previously texted was declined, and began bargaining with himself about watching pornography. Now, viewing more pornography than initially planned and masturbating compulsively, he describes "feeling empty, irritable, flat, tired, unable to function, having sleepless nights" and missing an appointment as a result. To establish enduring abstinence, he identifies a need to better structure his life at home during the lockdown, and to explore his child abuse and its link to his sexual fantasies.

\section{DISCUSSION AND CONCLUSIONS}

This case highlights that there may be increased susceptibility to substitute addictions due to individual (e.g. stress; coping skills; cognitive and affective responses), environmental (e.g. recovery support; access to substances and behaviors) and addiction behavior-related factors (e.g. history and pattern of appetitive effects). While substitutes do not necessarily portend a relapse, coupled with isolation, reduced recovery support and (negative) cognitive and affective responses to a lapse (i.e. the abstinence violation effect; Collins \& Witkiewitz, 2013), they can potentiate relapse to the former or a "new" behavior. That is, the role ascribed to the pandemic in relation to a lapse (and substitution) and how relapse is framed should it occur, has implications for the maintenance and re-establishment of recovery. Unaddressed addictive behaviors in a set of addictions can hinder stable recovery or lead to relapse in the abstained behavior. Thus, the lifelong recovery process must attend to all dynamics that heighten relapse risk (Schneider, Sealy, Montgomery, \& Irons, 2005). Unresolved childhood sexual abuse can play an etiological role in alcohol and sex addiction and can predispose one to relapse; resolution of trauma may be needed (Young, 1990).

Substitute addictions may have emerged during the pandemic given limited access and availability to certain substances and behaviors, whereas others (e.g. those facilitated by the internet) may be attainable and endure during and after the pandemic. Not all substitute behaviors will be genuine addictions. However, it is precisely this variability in addiction trajectories that addiction professionals must be aware of during and after the COVID-19 pandemic, and its potential for escalating addictions in the absence of recovery support (and the potential continuation of co-occurring problems such as trauma). Consequently, SUD services should elicit a comprehensive (substance and non-substance) assessment, address substitute behaviors within the therapeutic framework and incorporate this information into recovery care planning and support. To ameliorate loneliness, persons in or seeking recovery should be encouraged to maintain connections to social networks via online platforms or telephone and to seek professional help during periods of loss of control or distress (Király et al., 2020). Future research should explore whether the affective and cognitive processes at work following a lapse differ in 
the face of a pandemic, and the resultant implications for managing substitute addictions and fostering recovery.

\section{ETHICS}

The study was approved by the Humanities and Social Research Ethics Committee of the University of the Western Cape (Cape Town, South Africa) and was conducted in accordance with the Declaration of Helsinki. The subject was informed about the research and provided consent for the case study.

Funding sources: This work was supported by the National Research Foundation of South Africa (grants 107586 and 121068) and Ghent University's Special Research Fund (BOF) for Candidates from Developing Countries.

Authors' contribution: DS wrote the first draft of the case study, which was critically revised by WV, SYS, DB, SS and MF. All authors approved the final version of the manuscript for submission.

Conflict of interest: The authors declare no conflict of interest.

\section{REFERENCES}

Bőthe, B., Potenza, M. N., Griffiths, M. D., Kraus, S. W., Klein, V., Fuss, J., et al. (2020). The development of the Compulsive Sexual Behavior Disorder Scale (CSBD-19): An ICD-11 based screening measure across three languages. Journal of Behavioral Addictions, 9(2), 247-258. https://doi.org/10.1556/2006.2020. 00034.

Bőthe, B., Tóth-Király, I., Griffiths, M. D., Potenza, M. N., Orosz, G., \& Demetrovics, Z. (2020). Are sexual functioning problems associated with frequent pornography use and/or problematic pornography use? Results from a large community survey including males and females. Addictive Behaviors, 112, 106603. https://doi.org/10.1016/j.addbeh.2020.106603.

Bőthe, B., Tóth-Király, I., Potenza, M. N., Orosz, G., \& Demetrovics, Z. (2020c). High- frequency pornography use may not always be problematic. The Journal of Sexual Medicine, 17(4), 793-811. https://doi.org/10.1016/j.jsxm.2020.01.007.

Castro-Calvo, J., Ballester-Arnal, R., Potenza, M. N., King, D. L., \& Billieux, J. (2018). Does "forced abstinence" from gaming lead to pornography use? Insight from the April 2018 crash of Fortnite's servers. Journal of Behavioral Addictions, 7(3), 501502. https://doi.org/10.1556/2006.7.2018.78.

Collins, S. E., \& Witkiewitz, K. (2013). Abstinence violation effect. In M. D. Gellman, \& J. R. Turner (Eds.), Encyclopedia of behavioral medicine. Springer. https://doi.org/10.1007/978-14419-1005-9_623.

Degenhardt, L., Day, C., Gilmour, S., \& Hall, W. (2006). The "lessons" of the Australian "heroin shortage". Substance Abuse
Treatment, Prevention, and Policy, 1(1), 1-7. https://doi.org/10. 1186/1747-597X-1-11.

Dekkers, A., Vos, S., \& Vanderplasschen, W. (2020). "Personal recovery depends on NA unity": An exploratory study on recovery-supportive elements in Narcotics Anonymous Flanders. Substance Abuse Treatment, Prevention, and Policy, 15(1), 53. https://doi.org/10.1186/s13011-020-00296-0.

Dickenson, J. A., Gleason, N., Coleman, E., \& Miner, M. H. (2018). Prevalence of distress associated with difficulty controlling sexual urges, feelings, and behaviors in the United States. JAMA Network Open, 1(7), e184468-e184468. https://doi.org/10.1001/ jamanetworkopen.2018.4468.

Gooberman, L. (1974). Operation Intercept: The multiple consequences of public policy. New York, Pergamon Press. https://doi. org/10.1016/C2013-0-02597-2.

Griffiths, M. (2005). A 'components' model of addiction within a biopsychosocial framework. Journal of Substance Use, 10(4), 191-197. https://doi.org/10.1080/14659890500114359.

Grubbs, J. B. (2020). Porn use is up, thanks to the pandemic. The Conversation. April 8, 2020. Retrieved September 2, 2020, from, https://theconversation.com/pornuse-is-up-thanks-to-thepandemic-134972.

Kalema, D., Vindevogel, S., Derluyn, I., Baguma, P. K., Bannink, F., \& Vanderplasschen, W. (2019). Perspectives of alcohol treatment providers and users on alcohol addiction and its facilitating factors in Uganda and Belgium. Drugs: Education, Prevention \& Policy, 26(2), 184-194. https://doi.org/10.1080/ 09687637.2017.1381667.

Keen, H., Sathiparsad, R., \& Taylor, M. (2015). Prevalence of multiple addictions and current treatment by drug treatment centres in Durban, South Africa. Social Work, 51(2), 244-261.

Király, O., Potenza, M. N., Stein, D. J., King, D. L., Hodgins, D. C., Saunders, J. B., ... \& Abbott, M. W. (2020). Preventing problematic internet use during the COVID-19 pandemic: Consensus guidance. Comprehensive Psychiatry, 100, 152180. https://doi.org/10.1016/j.comppsych.2020.152180.

Kraus, S. W., Krueger, R. B., Briken, P., First, M. B., Stein, D. J., Kaplan, M. S., et al. (2018). Compulsive sexual behaviour disorder in the ICD-11. World Psychiatry: Official Journal of the World Psychiatric Association, 17(1), 109-110. https://doi.org/ 10.1002/wps.20499.

Lehmiller, J. J., Garcia, J. R., Gesselman, A. N., \& Mark, K. P. (2020). Less sex, but more sexual diversity: Changes in sexual behavior during the COVID-19 coronavirus pandemic. Leisure Sciences. https://doi.org/10.1080/01490400.2020.1774016.

Lim, M. S. M., Cheung, F. Y. L., Kho, J. M., \& Tang, C. K. (2020). Childhood adversity and behavioural addictions: The mediating role of emotion dysregulation and depression in an adult community sample. Addiction Research \& Theory, 28(2), 116123. https://doi.org/10.1080/16066359.2019.1594203.

Luthuli, T. (2020, June 5). Illicit trade in cigarettes and alcohol has thrived during lockdown. Retrieved from https://www. dailymaverick.co.za/opinionista/2020-06-05-illicit-trade-incigarettes-and-alcohol-has-thrived-during-lockdown/\#gsc. $\mathrm{tab}=0$.

Marlatt, G. A., \& George, W. H. (1984). Relapse prevention: Introduction and overview of the model. British Journal of 
Addiction, 79(4), 261-273. https://doi.org/10.1111/j.1360-0443. 1984.tb00274.x.

Marsden, J., Darke, S., Hall, W., Hickman, M., Holmes, J., Humphreys, K., ... \& West, R. (2020). Mitigating and learning from the impact of COVID-19 infection on addictive disorders. Addiction, 115(6), 1007-1010. https://doi.org/10.1111/add.15080.

Melemis, S. M. (2015). Relapse prevention and the five rules of recovery. Yale Journal of Biology \& Medicine, 88(3), 325.

Mestre-Bach, G., Blycker, G. R., \& Potenza, M. N. (2020). Pornography use in the setting of the COVID-19 pandemic. Journal of Behavioral Addictions, 9(2), 181-183. https://doi.org/ 10.1556/2006.2020.00015.

Mokone, T. (2020, April 29). Close to 200 alcohol establishments hit since start of lockdown - Bheki Cele. Retrieved from https:// www.timeslive.co.za/politics/2020-04-29-close-to-200-alcoholestablishments-hit-since-start-of-lockdown-bheki-cele/.

Pyatt, J. (2020, May 25). Fourteen people die and ten more are fighting for their lives after drinking home brew to get around South Africa alcohol ban. Retrieved from https://www. dailymail.co.uk/news/article-8355213/Fourteen-people-die-tenfighting-lives-drinking-home-brew-South-Africa.html.

Schneider, J. P., Sealy, J., Montgomery, J., \& Irons, R. R. (2005). Ritualization and reinforcement: Keys to understanding mixed addiction involving sex and drugs. Sexual Addiction of Compulsivity, 12(2-3), 121-148. https://doi.org/10.1080/107201 60500203468.

Sinclair, D. L., Sussman, S., Savahl, S., Florence, M., Adams, S., \& Vanderplasschen, W. (2020). Substitute addictions in persons with substance use disorders: A scoping review. Manuscript submitted for publication.

Slavin, M. N., Blycker, G. R., Potenza, M. N., Bőthe, B., Demetrovics, Z., \& Kraus, S. W. (2020). Gender-related differences in associations between sexual abuse and hypersexuality. The Journal of Sexual Medicine, 17(10), 2029-2038. https://doi.org/10.1016/j.jsxm.2020.07.008.

Slavin, M. N., Scoglio, A. A., Blycker, G. R., Potenza, M. N., \& Kraus, S. W. (2020). Child sexual abuse and compulsive sexual behavior:
A systematic literature review. Current Addiction Reports, 7(1): 76-88. https://doi.org/10.1007/s40429-020-00298-9.

Sundin, M., \& Lilja, J. (2019). Substance use and strategies to avoid relapses following treatment: A narrative approach with clients undertaking a twelve-step program in Sweden. Journal of Substance Use, 24(2), 125-129. http://doi.org/10.1080/14659891.2018.1523959.

Sussman, S. (2017). Substance and behavioral addictions: Concepts, causes, and cures. Cambridge University Press.

Sussman, S., Leventhal, A., Bluthenthal, R. N., Freimuth, M., Forster, M., \& Ames, S. L. (2011). A framework for the specificity of addictions. International Journal of Environmental Research and Public Health, 8(8), 3399-3415. https://doi.org/10.3390/ ijerph8083399.

Szymanski, D. M., \& Stewart-Richardson, D. N. (2014). Psychological, relational, and sexual correlates of pornography use on young adult heterosexual men in romantic relationships. The Journal of Men's Studies, 22(1), 64-82. https://doi.org/10.3149/ jms.2201.64.

Tadpatrikar, A., \& Sharma, M. K. (2018). Pornography as a replacement for substance use: An emerging approach to understand addiction mechanism. Open Journal of Psychiatry \& Allied Sciences, 9(2), 173-175. https://doi.org/10.5958/23942061.2018.00036.8.

The Betty Ford Institute Consensus Panel. (2007). What is recovery? A working definition from the betty Ford Institute. Journal of Substance Abuse Treatment, 33, 221-228. https://doi.org/10. 1016/j.jsat.2007.06.001.

Volkow, N. D. (2020). Collision of the COVID-19 and addiction epidemics. Annals of Internal Medicine, 173, 61-62. https://doi. org/10.7326/M20-1212.

Weatherburn, D., Jones, C., Freeman, K., \& Makkai, T. (2003). Supply control and harm reduction: Lessons from the Australian heroin 'drought'. Addiction, 98(1), 83-91. https://doi.org/ 10.1046/j.1360-0443.2003.00248.x.

Young, E. B. (1990). The role of incest issues in relapse. Journal of Psychoactive Drugs, 22(2), 249-258. https://doi.org/10.1080/ 02791072.1990 .10472547$. 